\title{
Endoscopic band ligation for a rectal Dieulafoy's lesion
}

\section{Naoto Iwai, Takashi Okuda, Toshifumi Tsuji, Keizo Kagawa}

Fukuchiyama City Hospital, Kyoto, Japan

An 88-year-old man was transported to our hospital because of severe hematochezia with circulatory failure. He had a history of Alzheimer's disease, but had no history of medication with anticoagulants. After blood transfusion, contrast-enhanced computed tomography revealed an extravasation in the rectum (Fig. 1). He underwent emergency colonoscopy for hemostasis. The colonoscopic examination revealed a bulgy vessel with a minimal mucosal defect, which was diagnosed as rectal Dieulafoy's lesion (Fig. 2A). First, thermal coagulation using hemostatic forceps was performed. However, spurting bleeding occurred, and the hemostasis with hemostatic forceps failed (Fig. 2B). Thus, endoscopic band ligation (EBL) was performed to achieve hemostasis (Fig. 2C) without rebleeding.

Dieulafoy's lesions are characterized by a protruding vessel without a surrounding ulcer [1]. They can cause acute bleeding that results in hypovolemic shock, necessitating the urgent application of endoscopic hemostasis via techniques such as endoclip, thermal coagulation, injection of hypertonic saline epinephrine and EBL. Although EBL has been widely used for the treatment of esophageal varices, it has recently

Department of Gastroenterology and Hepatology, Fukuchiyama City Hospital, Kyoto, Japan

Conflict of Interest: None

Correspondence to: Naoto Iwai, MD, PhD, Department of Gastroenterology and Hepatology, Fukuchiyama City Hospital, 231 Atsunaka-cho, Fukuchiyama-city, Kyoto 620-8505, Japan, e-mail: na-iwai@koto.kpu-m.ac.jp

Received 13 December 2019; accepted 16 December 2019 published online 12 February 2020

DOI: https://doi.org/10.20524/aog.2020.0454
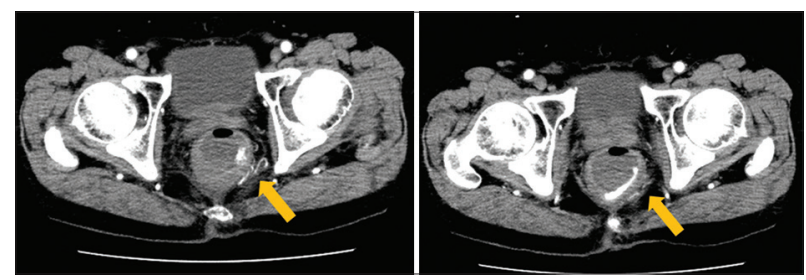

Figure 1 Contrast-enhanced computed tomography showing an extravasation in the rectum (yellow arrow)

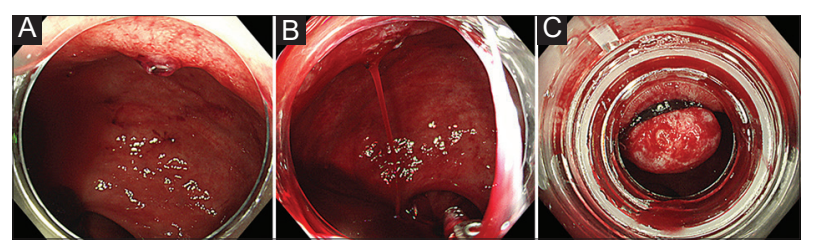

Figure 2 (A) Colonoscopy image of a rectal Dieulafoy's lesion. (B) Colonoscopy image of spurting bleeding from the lesion. (C) Colonoscopy image of endoscopic band ligation

attracted attention as a feasible and safe treatment for colonic diverticular bleeding [2]. Considering the endoscopic features of Dieulafoy's lesions, EBL could be recommended as an effective management strategy for patients with this condition.

\section{References}

1. Baettig B, Haecki W, Lammer F, Jost R. Dieulafoy's disease: endoscopic treatment and follow up. Gut 1993;34:1418-1421.

2. Ishii $\mathrm{N}$, Itoh $\mathrm{T}$, Uemura $\mathrm{M}$, et al. Endoscopic band ligation with a water-jet scope for the treatment of colonic diverticular hemorrhage. Dig Endosc 2010;22:232-235. 